\title{
Fabrication and Properties of Electrospun and Electrosprayed Polyethylene Glycol/Polylactic Acid (PEG/PLA) Films
}

\author{
Weichang Ke ${ }^{1}$, Xiang Li $^{2}$, Mengyu Miao ${ }^{2}$, Bing Liu ${ }^{1}$, Xiaoyu Zhang ${ }^{2}$ and Tong Liu ${ }^{2, *(D)}$ \\ 1 China Tobacco Hubei Industrial LLC, Wuhan 430040, China; kewch@hbtobacco.cn (W.K.); \\ jerry.lb@163.com (B.L.) \\ 2 School of Power and Mechanical Engineering, Wuhan University, Wuhan 430072, China; \\ 2017302650114@whu.edu.cn (X.L.); 2015302650129@whu.edu.cn (M.M.); 2016302650148@whu.edu.cn (X.Z.) \\ * Correspondence: liu_tong@whu.edu.cn
}

Citation: Ke, W.; Li, X.; Miao, M.; Liu, B.; Zhang, X.; Liu, T. Fabrication and Properties of Electrospun and Electrosprayed Polyethylene Glycol/Polylactic Acid (PEG/PLA) Films. Coatings 2021, 11, 790. https:// doi.org/10.3390/coatings 11070790

Academic Editors: Csaba Balázsi and Kevin Plucknett

Received: 10 June 2021

Accepted: 28 June 2021

Published: 30 June 2021

Publisher's Note: MDPI stays neutra with regard to jurisdictional claims in published maps and institutional affiliations.

Copyright: (c) 2021 by the authors. Licensee MDPI, Basel, Switzerland. This article is an open access article distributed under the terms and conditions of the Creative Commons Attribution (CC BY) license (https:/ / creativecommons.org/licenses/by/ $4.0 /)$.

\begin{abstract}
Polylactic acid (PLA) film is an alternative filter material for heat-not-burn (HNB) tobacco, but its controllability in cooling performance is limited. In this work, polyethylene glycol (PEG) was introduced to form a polyethylene glycol/polylactic acid (PEG/PLA) film by electrospinning or electrospraying techniques to enhance the cooling performance, due to its lower glass transition and melting temperatures. The PEG/PLA films with typical electrospun or electrosprayed morphologies were successfully fabricated. One typical endothermic peak at approximately $65{ }^{\circ} \mathrm{C}$ was clearly observed for the melting PEG phase in the heating process, and the re-crystallization temperature represented by an exothermic peak was effectively lowered to $90-110{ }^{\circ} \mathrm{C}$ during the cooling process, indicating that the cooling performance is greatly enhanced by the introduction of the PEG phase. Additionally, the wetting properties and adsorption properties were also intensively studied by characterizing the contact angles, and the as-prepared PEG/PLA films all showed good affinity to water, 1,2-propandiol and triglyceride. Furthermore, the PEG/PLA film with a PLA content of $35 \mathrm{wt} . \%$ revealed the largest elasticity modulus of $378.3 \pm 68.5 \mathrm{MPa}$ and tensile strength of $10.5 \pm 1.1 \mathrm{MPa}$. The results achieved in this study can guide the development of other filter materials for HNB tobacco application.
\end{abstract}

Keywords: polylactic acid; polyethylene glycol; electrospinning; heat-not-burn tobacco; cooling performance

\section{Introduction}

Smoking has an extremely long history and is deeply rooted in society. The total consumption of conventional cigarettes, the most popular tobacco product, reached 5.7 trillion in 2016 [1]. As a result, smoked cigarette butts have become one of largest contributors of litter in the world. It has been largely reported that smoked cigarette butts contain over 7000 chemicals, including many harmful and/or carcinogenic effects, which can be released or leached after being released into the environment [2-4]. Therefore, new cigarette types, such as heat-not-burn (HNB) tobacco and electronic cigarettes, have been developed to overcome these threats to life and to the environment. HNB tobacco devices heat tobacco but do not burn it, which can reduce the release of harmful products from its combustion [5-7]. Bentley et al. reported that the emission of toxic products can be reduced by approximately 95\% [8]. However, harmful gases, including formaldehyde, acetaldehyde and acrolein, may still be generated in mainstream smoke due to the use of propylene glycol and vegetable glycerin in HNB tobacco [9,10].

Recently, adsorbing materials, such as zeolites, metal-organic frameworks, activated carbon, fibers, coordination polymers and carbon nanotubes, have been developed to further remove the toxic chemicals in mainstream smoke due to their excellent adsorbing properties provided by their extremely high specific surface areas [11-13]. However, there are still many limitations in processing and production, such as the material safety, high 
cost and tedious preparation process. Therefore, it is critical to design and manufacture novel, more efficient adsorbing materials for HNB tobacco products.

Biodegradable natural polymer polylactic acid (PLA) is an abundant renewable biomass polymer, which has been applied as an HNB filter material due to its low cost, lightweight and apparently environmentally superiority alternative to synthetic materials [14-16]. It is proven that the harmful pollutants to the environment during the smoking process have been greatly eliminated by the application of PLA filters for HNB tobacco, thus presenting strongly positive effects on the economy, human beings and society [17]. However, the cooling performance can only be narrowly tailored by the use of single-phase PLA. Moreover, the controllability in cooling properties is limited.

Currently, the introduction of polymer materials with lower glass transition and melting temperatures to form blending materials has been considered as one of the most effective strategies to manipulate the cooling performance as the as-prepared blending materials effectively exhibit lowered thermal properties, including glass transition temperature, melting temperature and recrystallization temperature [18-23]. Polyethylene glycol (PEG) material, which has a much lower glass transition temperature (below $40^{\circ} \mathrm{C}$ ) and melting temperature (lower than $70^{\circ} \mathrm{C}$ ) than those for classic PLA filter materials, is one of the most commonly used polymer additives to adjust cooling properties due to its biodegradability, good cooling performance, easy processing and low cost [18-21]. Therefore, PLA and PEG materials are chosen as the main material and polymer additive to form polyethylene glycol/polylactic acid (PEG/PLA) blending film, respectively, and the cooling performance of PEG/PLA blending material can be enhanced by the glass transition and melting of PEG phase at a lower temperature than PLA material, thus leading to a reduced outlet temperature of the filter of HNB tobacco.

The objective of this work is to prepare novel films with high cooling performance, good wetting and adsorption properties, as well as considerable mechanical properties for HNB tobacco application. The electrospinning technique has been considered as one of the most efficient ways to fabricate continuous fibers in the submicron to nanometer scale range, and the microstructure of the fibers is highly dependent on electrospinning parameters such as precursor electrospinning solution, operating voltage and the distance from the collector to the needle [23-35]. Therefore, in the present work, three typical electrospun/electrosprayed PEG/PLA films with different morphologies were prepared by using the simple electrospinning or electrospray method and adjusting the PLA content and precursor electrospinning solution. Their morphologies were measured by using scanning electron microscopy (SEM), while the thermal properties were determined by differential scanning calorimetry (DSC) and thermal conductivity meters (TCM). Finally, the wetting properties and mechanical properties were evaluated using the contact angle meter and universal material testing machine, respectively.

\section{Materials and Methods}

\subsection{Materials}

Polylactic acid (PLA) with an average molecular weight (Mw) of $80,000 \mathrm{~g} / \mathrm{mol}$ was purchased from Macklin Biochemical Co. Ltd (Shanghai, China). Polyethylene glycol (PEG) with Mw of 10,000 g/mol was supplied by Aladdin Biochemical Technology Co. Ltd (Shanghai, China). Dimethylacetamide (DMAc), the solvent of the electrospinning solution, was purchased from Sinopharm Chemical Reagent Co., Ltd (Shanghai, China). Note that the chemicals used in this work were all of analytical reagent (AR) grade.

\subsection{Preparation and Characterization of the Spinning Solutions}

PLA and PEG were dissolved in DMAc solvent and stirred at $50{ }^{\circ} \mathrm{C}$ till the homogeneous spinning solutions were obtained, and the composition parameters of three spinning solutions used in this work are listed in Table 1. For simplification, these three spinning solutions were marked as PLA25, PLA35 and PLA45, respectively. 
Table 1. Composition parameters of the three spinning solutions used in this work.

\begin{tabular}{cccc}
\hline \multirow{2}{*}{ Sample } & \multicolumn{3}{c}{ Composition (wt.\%) } \\
\cline { 2 - 4 } & DMAc & PEG & PLA \\
\hline PLA25 & 70 & 5 & 25 \\
PLA35 & 60 & 5 & 35 \\
PLA45 & 50 & 5 & 45 \\
\hline
\end{tabular}

\subsection{Electrospinning Conditions}

A commercial electrospinning apparatus (Model SS-1, Beijing Ucalery Technology Development Co. Ltd., Beijing, China) was applied to prepare PEG/PLA fiber films. A grounded aluminum cylinder with an outer diameter of $10.0 \mathrm{~cm}$ and a length of $32.0 \mathrm{~cm}$, which was covered by silicon paper, was used as the fiber collector, and its rotation speed was fixed at $30 \mathrm{rpm}$. During the electrospinning process, the distance from the collector to the needle was fixed at $12.0 \mathrm{~cm}$. Meanwhile, the flow rate of the solution was precisely controlled at $2 \mathrm{~mL} / \mathrm{h}$ by using a syringe pump, while the working temperature and the relative humidity in the compartment were controlled at approximately $40{ }^{\circ} \mathrm{C}$ and $35 \%$ relative humidity $(\mathrm{RH})$. The high voltage applied in the electrospinning/electrospray process was $+15 \mathrm{kV}$. The PEG/PLA fiber films obtained by electrospinning for more than $3 \mathrm{~h}$ were dried at $50{ }^{\circ} \mathrm{C}$ in a vacuum oven for $5 \mathrm{~h}$ to completely remove the residual solvent. The obtained PEG/PLA films were named PLA25, PLA35 and PLA45, respectively.

\subsection{Characterization}

The morphology of the PEG/PLA films was examined by using scanning electron microscopy (SEM; MIRA 3, Tescan, Brno, Czech), which was then further analyzed by using the ImageJ software (ImageJ bundled with 64-bit Java 1.8.0_172, National Institutes of Health, Bethesda, MD, USA) to calculate the diameters of the fibers.

The Fourier transform infrared (FTIR) spectra of these films were collected by using an FTIR spectrometer (Nicolet 5700, Thermo Fisher, Waltham, MA, USA).

The thermal characteristics of these films were recorded by differential scanning calorimetry (DSC, Q2000, TA Instruments, New Castle, DE, USA) in the temperature range from 30 to $200{ }^{\circ} \mathrm{C}$ under pure $\mathrm{N}_{2}$ conditions with a flow rate of $30 \mathrm{~mL} / \mathrm{min}$. For each sample, a $10 \mathrm{mg}$ PEG/PLA film was placed in an aluminum crucible and then sealed hermetically during a heating and cooling cycle with a heating and cooling rate of $5{ }^{\circ} \mathrm{C} / \mathrm{min}$. The phases composition of the fiber films was detected by using an X-ray diffractometer

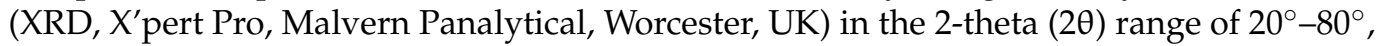
while the three films with a size of $50 \times 50 \mathrm{~mm}$ were exposed to pure $\mathrm{N}_{2}$ to measure their corresponding thermal conductivities at $30^{\circ} \mathrm{C}$ by using a thermal conductivity meters (TPS 2500S, Hot Disk, Göteborg, Sweden).

The surface wetting properties of the three PEG/PLA films to water, glycerol and 1,2-propanediol were determined by performing contact angle (CA) measurements via a CA meter (JC2000C, POWEREACH, Shanghai, China) to study their adsorption properties. The average $C A$ values were obtained based on at least 5 independent measurements for each sample.

The mechanical properties of these PEG/PLA films were determined using a universal material testing machine (CMT 6103, MTS Systems Corporation, Yokohama, Japan). The stretching rate was $25 \mathrm{~mm} / \mathrm{min}$ with an initial length between the clamps of $10 \mathrm{~mm}$ at $25^{\circ} \mathrm{C}$. All samples with a size of $30 \mathrm{~mm}$ (length) $\times 3 \mathrm{~mm}$ (width) $\times 0.5 \mathrm{~mm}$ (thickness) were cut along the collector rotation direction, and at least 5 samples for each film were tested to calculate the average values for the interpretation of the results. 


\section{Results and Discussion}

\subsection{Morphology and Phase Composition}

The microstructure of the as-prepared PEG/PLA films shown in Figure 1 significantly changed due to varying the precursor electrospinning solution. PLA25 and PLA35 PEG/PLA films exhibited typical morphologies for the electrospinning method [23-35], while the PLA45 PEG/PLA film showed the characteristic electrosprayed microstructure [33-35]. For the PLA25 film derived from solution PLA25 with the lowest PLA content of $25 \mathrm{wt} . \%$, the outerdiameter (O.D.) of the electrospun PEG/PLA fibers is in the range of $0.10-0.19 \mu \mathrm{m}$, while the calculated average O.D. value is $0.14 \mu \mathrm{m}$ (Figure 1A,a). As the PLA content increased to $35 \mathrm{wt} . \%$, the O.D. of the electrospun PEG/PLA fibers strongly increased to $0.33-2.00 \mu \mathrm{m}$, with an average value of $0.80 \mu \mathrm{m}$ (Figure 1B,b). These phenomena can be explained by the increased viscosity of the solutions induced by the decreased DMAc solvent content and increased PLA binder content, which is also consistent with the previously reported literature [33-37]. However, when further increasing the PLA content to $45 \mathrm{wt} . \%$, no fiber was formed, but homogeneous spherical microsize particles were formed by the PLA45 film (Figure 1C,c), which may be related to the solubility in the solvent, where the intrachain interactions may result in the polymer chains coiling on themselves to form spherical microsize particles [33-35].

Figure 2 shows the XRD patterns of three electrospun/electrosprayed PEG/PLA films mentioned above. Two typical diffraction peaks for PEG (PDF No: 50-2158) and PLA (PDF No: 49-2174), as well as an amorphous bump centered at approximately $23^{\circ}$, can be clearly observed in the 2-theta range of $10^{\circ}-40^{\circ}$, indicating that these PEG/PLA films are a mixture of amorphous phase and crystalline phase, and no secondary phase was formed during the preparation process. In addition, it was found that the signal of the PLA phase became more observable, while the diffraction peaks for the PEG phase became weaker for the three PEG/PLA films, which can be explained by the gradual increase in PLA content.

Figure 3 shows the FTIR infrared absorption spectra of the three PEG/PLA films. It was noticed that with the increasing PLA content in the films, the absorption bands located at approximately 867,1161 and $3500 \mathrm{~cm}^{-1}$, which can be attributed to the $\mathrm{O}-\mathrm{H}$ stretch and associated with PEG content [38], receded. Meanwhile, the $\mathrm{C}=\mathrm{O}$ stretching vibration peak at $1758 \mathrm{~cm}^{-1}$ [39], which can be used to reflect PLA content, was enhanced. These results are strongly consistent with the fact that the PLA content is gradually increased, and no obvious reaction occurs during the preparation process. 


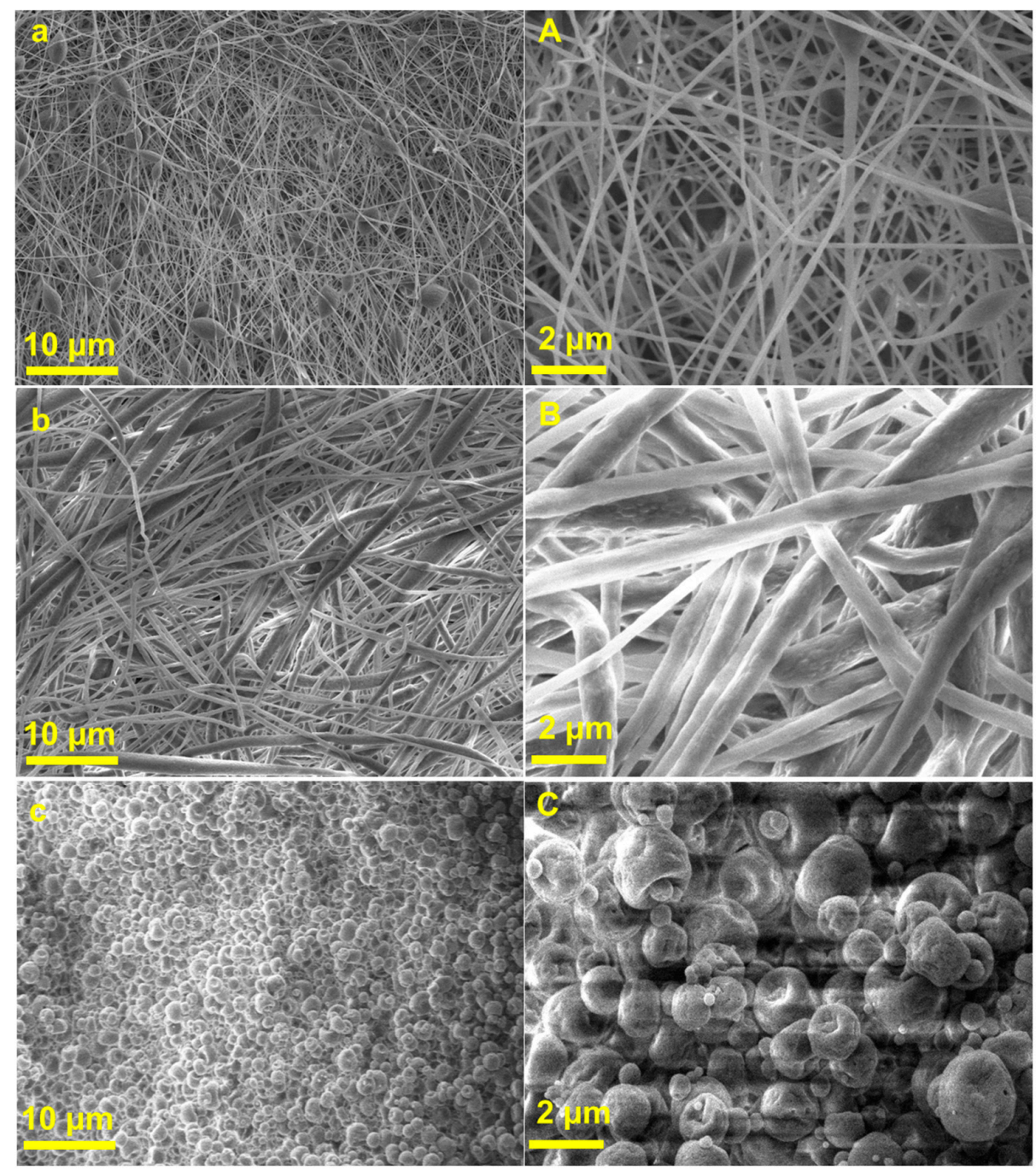

Figure 1. SEM images of (a,A) PLA25, (b,B) PLA 35 and (c,C)PLA45 PEG/PLA films with the magnification of $(\mathbf{a}-\mathbf{c}) 5000 \times$ and $(\mathbf{A}-\mathbf{C}) 20,000 \times$.

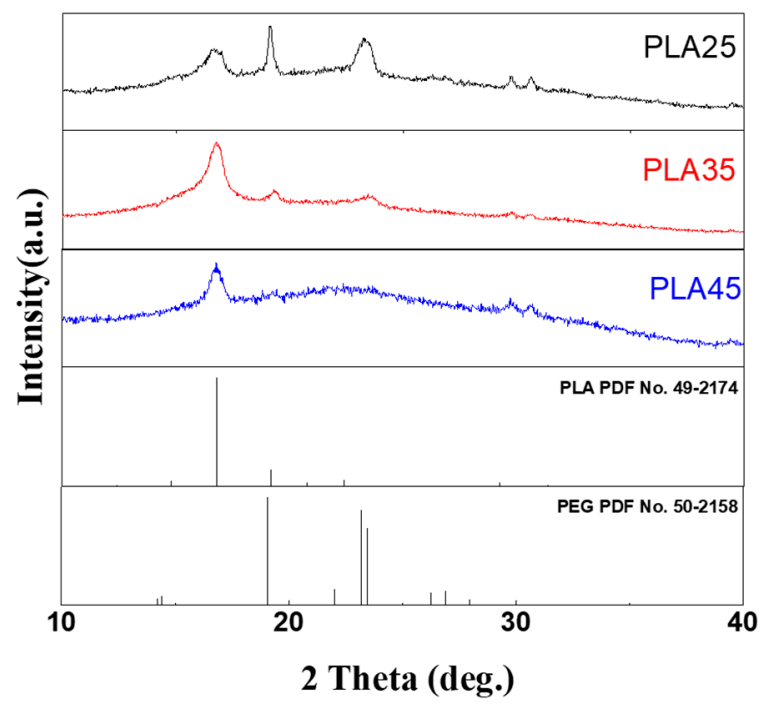

Figure 2. XRD patterns of the three electrospun/electrosprayed PEG/PLA films. (Note that the PDF card numbers for neat PEG and PLA materials are both obtained from MDIJade 6.5 software with the 2004 PDF database.). 


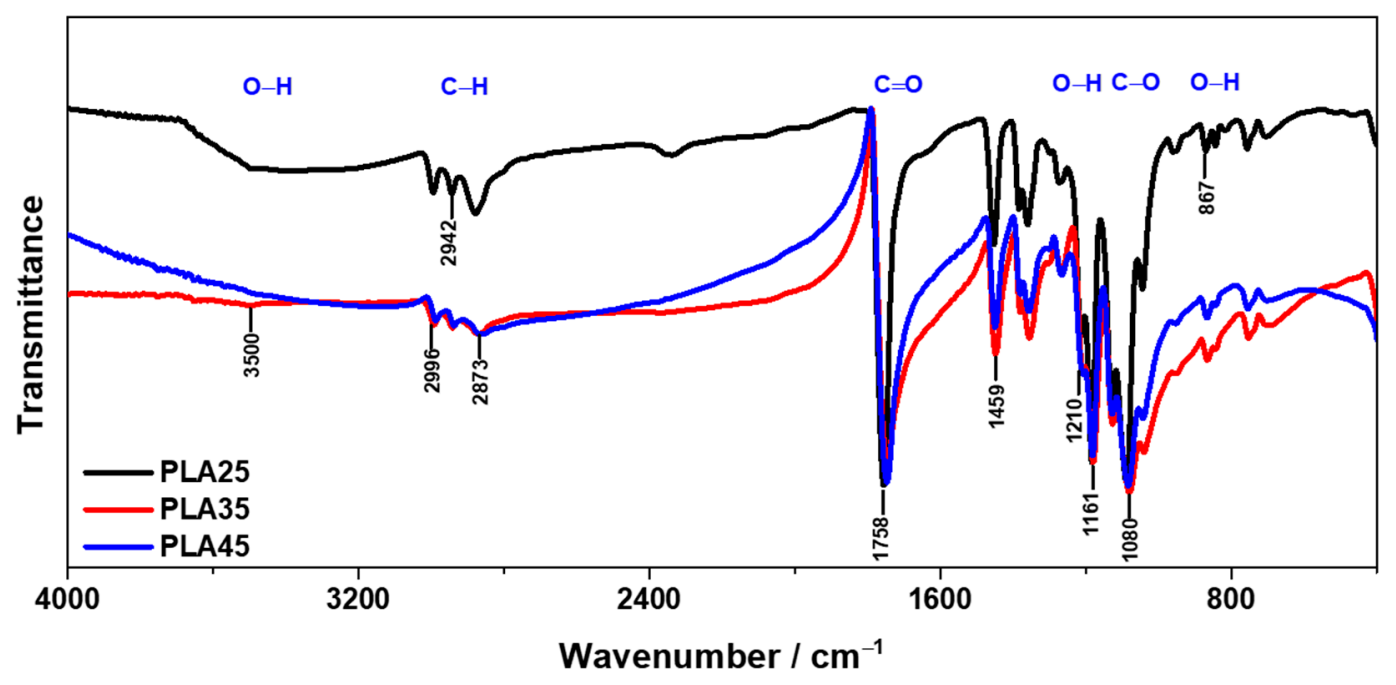

Figure 3. FTIR spectra of the three electrospun/electrosprayed PEG/PLA films.

\subsection{Thermal Properties}

DSC curves of the three electrospun/electrosprayed PEG/PLA films were measured in the temperature range of $25-200{ }^{\circ} \mathrm{C}$ with a cooling and heating rate of $5{ }^{\circ} \mathrm{C} / \mathrm{min}$ and holding at $200^{\circ} \mathrm{C}$ for $30 \mathrm{~min}$ to study the thermal transition properties of these samples. Melting temperature, glass transition temperature and crystallization temperature, as well as exothermic and endothermic heat, can be determined in the DSC curves. As shown in Figure 4, in the temperature range of $25-100{ }^{\circ} \mathrm{C}$, during the heating process, typical endothermic peaks at approximately $65^{\circ} \mathrm{C}$ could be observed, which are possibly attributed to the glass transition of PLA phase as well as the melting of PEG phase. However, no characteristic peak for the glass transition of PLA phase, a step change in the base line of the scan at approximately $65^{\circ} \mathrm{C}$, was observed. A possible reason for this is that the endothermic peak for the glass transition of PLA phase may be buried due to the stronger melting peak of PEG phase, which can be confirmed by the lowered strength of the endothermic peak with the increasing amount of PLA phase. It should be highlighted that the endothermic peak for the melting of PEG phase can serve as the additional heat absorber during the cooling process, thus reducing the temperature of the flowing gas and improving the cooling performance of PLA material. The characteristic endothermic peak with an onset temperature of approximately $160^{\circ} \mathrm{C}$ is ascribed to the melting of PEG/PLA films, which is lower than approximately $170{ }^{\circ} \mathrm{C}$ for PLA phase [16]. At the same time, the only typical exothermic peak observed at $90-110^{\circ} \mathrm{C}$ during the cooling process is probably associated with the recrystallization of PEG/PLA composite materials, and the temperature is obviously lower than that for pure PLA material [16]. These results, including the low-temperature endothermal peak at $65^{\circ} \mathrm{C}$ for melting PEG phase, decreased melting temperature from 170 to $160^{\circ} \mathrm{C}$ and lowered onset recrystallization from approximately 130 to $110^{\circ} \mathrm{C}$, indicate that the addition of PEG can effectively improve the cooling performance, and the increase in PEG content can further optimize the cooling performance. Note that a small exothermic peak was observed at approximately $70{ }^{\circ} \mathrm{C}$, which is possibly ascribed to the evaporation of the remaining DMAc solvent in the film.

Figure 5 shows the thermal conductivities of the three electrospun/electrosprayed PEG/PLA films measured at $30^{\circ} \mathrm{C}$. The thermal conductivity effectively increased from $0.1072 \mathrm{~W} \cdot \mathrm{m}^{-1} \cdot \mathrm{K}^{-1}$ for the PLA25 film to 0.2046 and $0.2237 \mathrm{~W} \cdot \mathrm{m}^{-1} \cdot \mathrm{K}^{-1}$ for the PLA35 film and the PLA45 film, respectively. These results imply that a higher PLA content and lower porosity in the electrospun/electrosprayed PEG/PLA films can benefit heat transfer and can further enhance the cooling performance. 


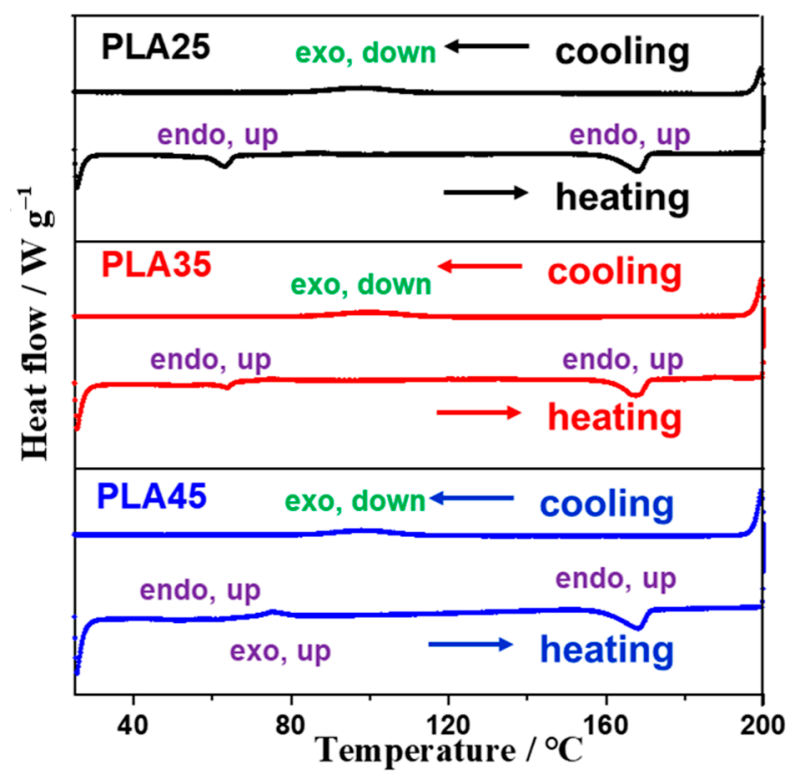

Figure 4. DSC curves of the three electrospun/electrosprayed PEG/PLA films.

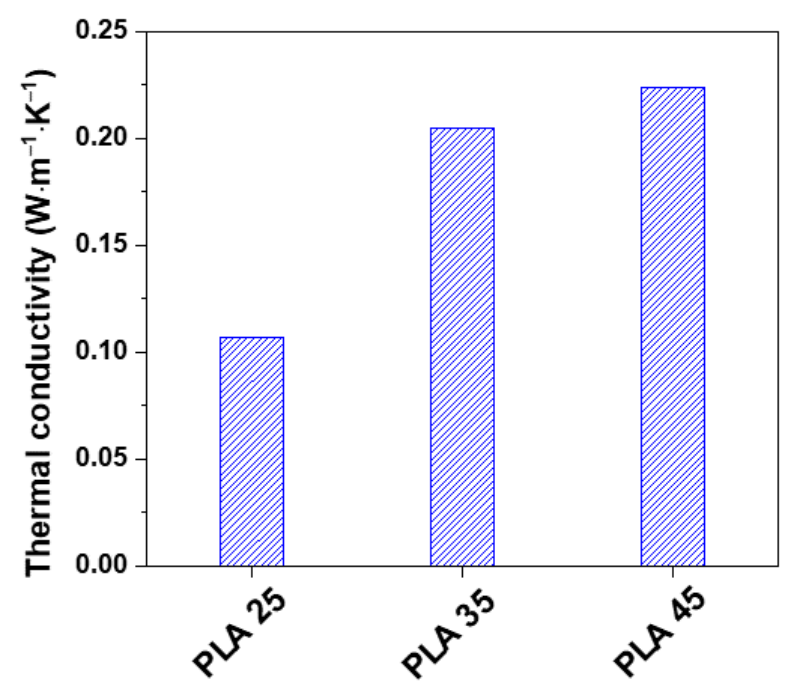

Figure 5. Thermal conductivities of the three electrospun/electrosprayed PEG/PLA films measured at $30{ }^{\circ} \mathrm{C}$.

\subsection{Wetting and Adsorption Properties}

The wetting properties of the three electrospun/electrosprayed PEG/PLA films towards water, 1,2-propanediol and triglyceride were also studied and are summarized in Figure 6 . The contact angles were $88.4^{\circ} \pm 1.5^{\circ}, 34.4^{\circ} \pm 1.7^{\circ}$ and $42.3^{\circ} \pm 1.2^{\circ}$ when the PLA25 film was exposed to water, 1,2-propandiol and triglyceride, respectively. As the PLA content increased to $35 \mathrm{wt} . \%$, the corresponding contact angle values for the PLA35 film gradually increased to $111.4^{\circ} \pm 0.8^{\circ}, 36.7^{\circ} \pm 3.6^{\circ}$ and $51.2^{\circ} \pm 2.5^{\circ}$, respectively. However, by further increasing PLA content, the contact angle to water slightly decreased to $100.9^{\circ} \pm 3.2^{\circ}$, while the values to 1,2 -propanediol and triglyceride continually increased to $43.7^{\circ} \pm 2.8^{\circ}$ and $53.0^{\circ} \pm 3.5^{\circ}$, respectively. The increase in contact angle value implies the decrease in wetting properties and adsorption properties of the films, which may be explained by the increased PLA content with lower adsorption properties [40]. 


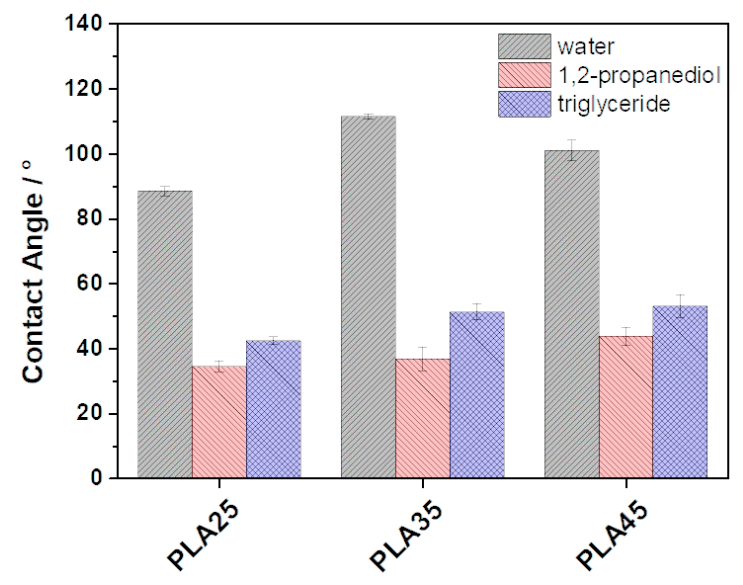

Figure 6. Contact angles for the three electrospun/electrosprayed PEG/PLA films.

\subsection{Mechanical Properties}

The typical strain-stress curves for three different PEG/PLA films shown in Figure 7 were measured by using the tension method. The mechanical properties, involving maximum elasticity modulus, tensile break stress, tensile strength, tensile yield stress and maximum force, are summarized in Table 2. It was found that the PLA35 film exhibited the largest value with the maximum elasticity modulus of $378.3 \pm 68.5 \mathrm{MPa}$, the tensile break stress of $4.3 \pm 0.5 \mathrm{MPa}$, the tensile strength of $10.5 \pm 1.1 \mathrm{MPa}$, the tensile yield stress of $9.5 \pm 1.0 \mathrm{MPa}$ and the maximum force of $0.31 \pm 0.03 \mathrm{~N}$, respectively. The PLA45 film showed the peak tensile strain at break of $67.9 \% \pm 21.4 \%$, while the PLA25 film revealed the worst mechanical properties. The mechanical properties are different for these three films, which is possibly attributed to their different porosities and morphologies, requiring further study in the future.

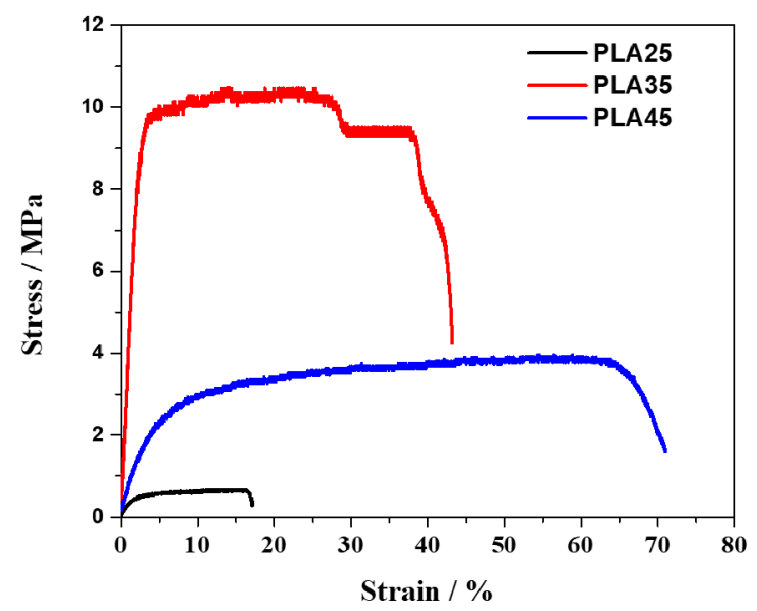

Figure 7. Strain-stress curves for the three electrospun/electrosprayed PEG/PLA films.

Table 2. Summary of the mechanical properties of the three electrospun/electrosprayed PEG/PLA films.

\begin{tabular}{cccc}
\hline Mechanical Property & PLA25 & PLA35 & PLA45 \\
\hline Elasticity modulus $(\mathrm{MPa})$ & $20.1 \pm 4.0$ & $378.3 \pm 68.5$ & $50.0 \pm 16.4$ \\
Tensile strain at break $(\%)$ & $18.4 \pm 3.6$ & $43.0 \pm 11.6$ & $67.9 \pm 21.4$ \\
Tensile break stress $(\mathrm{MPa})$ & $(3.0 \pm 0.4) \times 10^{-1}$ & $4.3 \pm 0.5$ & $1.4 \pm 0.3$ \\
Tensile strength $(\mathrm{MPa})$ & $0.7 \pm 0.1$ & $10.5 \pm 1.1$ & $3.4 \pm 0.7$ \\
Tensile yield stress $(\mathrm{MPa})$ & $(5.5 \pm 1.4) \times 10^{-1}$ & $9.5 \pm 1.0$ & $2.3 \pm 0.5$ \\
Maximum force $\left(\times 10^{-1} \mathrm{~N}\right)$ & $1.3 \pm 0.2$ & $3.1 \pm 0.3$ & $2.1 \pm 0.5$ \\
\hline
\end{tabular}


Consequently, the PLA35 film with wider fibers and lower porosity is the optimal film due to its desirable cooling performance and mechanical strength, as well as considerable wetting and adsorption properties to water, 1,2-propanediol and triglyceride, as summarized in Table 3.

Table 3. Summary of the physicochemical properties of the three electrospun/electrosprayed PEG/PLA films.

\begin{tabular}{|c|c|c|c|c|}
\hline \multicolumn{2}{|c|}{ Physicochemical Property } & PLA25 & PLA35 & PLA45 \\
\hline \multicolumn{2}{|c|}{ Morphology } & fibers $(0.14 \mu \mathrm{m})$ & fibers $(0.80 \mu \mathrm{m})$ & particles \\
\hline \multicolumn{2}{|c|}{ Thermal properties } & good & good & good \\
\hline & $\mathrm{H}_{2} \mathrm{O}$ & $88.4 \pm 1.5$ & $111.4 \pm 0.8$ & $100.9 \pm 3.2$ \\
\hline Wetting properties & 1,2-propandiol & $34.4 \pm 1.7$ & $36.7 \pm 3.6$ & $43.7 \pm 2.8$ \\
\hline ntact Angle, ') & triglyceride & $42.3 \pm 1.2$ & $51.2 \pm 2.5$ & $53.0 \pm 3.5$ \\
\hline \multicolumn{2}{|c|}{$\begin{array}{l}\text { triglyceride } \\
\text { Mechanical properties }\end{array}$} & worst & best & moderate \\
\hline
\end{tabular}

\section{Conclusions}

Herein, three PEG/PLA films with different morphologies were successfully prepared by varying the PLA content in the precursor solutions and by using the electrospinning or electrospray method. The morphology, phase composition, thermal properties, wetting properties and mechanical properties of the films were intensively studied, finding that the cooling performance of the PLA film was effectively improved by the addition of PEG due to its lower glass transition temperature and melting temperature. Moreover, the mechanical properties of the PEG/PLA films are greatly affected by their composition and morphology. It was demonstrated that the PLA35 film fabricated by the precursor electrospinning solution with a PLA content of $35 \mathrm{wt} . \%$ exhibited a desirable cooling performance, the best mechanical properties and acceptable wetting and adsorption properties towards water, 1,2-propanediol and triglyceride. As a result, the PLA35 film is a potential alternative film for HNB tobacco application.

Author Contributions: Conceptualization, W.K. and T.L.; methodology, X.L; software, X.L.; validation, M.M, B.L. and X.Z.; formal analysis, W.K.; investigation, W.K., X.L., M.M., B.L., X.Z. and T.L.; writing—original draft preparation, T.L.; writing-review and editing, W.K and T.L. All authors have read and agreed to the published version of the manuscript.

Funding: This research was funded by the Science and Technology Project of China Tobacco Hubei Industrial LLC, Grant No.: 2019420000340371.

Institutional Review Board Statement: Not applicable.

Informed Consent Statement: Not applicable.

Data Availability Statement: Data sharing not applicable.

Conflicts of Interest: The authors declare no conflict of interest.

\section{References}

1. Atlas, T.; Atlas, C.T. TitleCigarette Consumption, 2016. Available online: https://tobaccoatlas.org/topic/consumption/ (accessed on 10 July 2019).

2. Baran, W.; Madej-Knysak, D.; Sobczak, A.; Adamek, E. The influence of waste from electronic cigarettes, conventional cigarettes and heat-not-burn tobacco products on microorganisms. J. Hazard. Mater. 2020, 385, 121591. [CrossRef]

3. Benjamin, R.M. Exposure to tobacco smoke causes immediate damage: A report of the surgeon general. Public Health Rep. 2011, 126, 158-159. [CrossRef] [PubMed]

4. Centers for Disease Control and Prevention, National Biomonitoring Program, Tobacco. 2016. Available online: https://www. cdc.gov/biomonitoring/tobacco.html (accessed on 19 September 2019).

5. Shein, M.; Jeschke, G. Comparison of free radical levels in the aerosol from conventional cigarettes, electronic cigarettes, and heat-not-burn tobacco products. Chem. Res. Toxicol. 2019, 32, 1289-1298. [CrossRef]

6. Azzopardi, D.; Patel, K.; Jaunky, T.; Santopietro, S.; Camacho, O.M.; McAughey, J.; Gaça, M. Electronic cigarette aerosol induces significantly less cytotoxicity than tobacco smoke. Toxicol. Mech. Method. 2016, 26, 477-491. [CrossRef] [PubMed] 
7. Simonavicius, E.; McNeill, A.; Shahab, L.; Brose, L.S. Heat-not-burn tobacco products: A systematic literature review. Tob. Control. 2019, 28, 582-594. [CrossRef] [PubMed]

8. Bentley, M.C.; Almstetter, M.; Arndt, D.; Knorr, A.; Martin, E.; Pospisil, P.; Maeder, S. Comprehensive chemical characterization of the aerosol generated by a heated tobacco product by untargeted screening. Anal. Bioanal. Chem. 2020, 412, 2675-2685. [CrossRef]

9. Kim, Y.-H.; An, Y.-J. Development of a standardized new cigarette smoke generating (SNCSG) system for the assessment of chemicals in the smoke of new cigarette types (heat-not-burn (HNB) tobacco and electronic cigarettes (E-Cigs)). Environ. Res. 2020, 185, 109413. [CrossRef] [PubMed]

10. Uchiyama, S.; Noguchi, M.; Takagi, N.; Hayashida, H.; Inaba, Y.; Ogura, H.; Kunugita, N. Simple determination of gaseous and particulate compounds generated from heated tobacco products. Chem. Res. Toxicol. 2018, 31, 585-593. [CrossRef]

11. Fu, Z.; Zhou, S.; Xia, L.; Mao, Y.; Zhu, L.; Cheng, Y.; Wang, A.; Zhang, C.; Xu, W. Juncus effusus fiber-based cellulose cigarette filter with 3D hierarchically porous structure for removal of PAHs from mainstream smoke. Carbohyd. Polym. 2020, 241, 116308. [CrossRef]

12. Branton, P.; Lu, A.-H.; Schüth, F. The effect of carbon pore structure on the adsorption of cigarette smoke vapour phase compounds. Carbon 2009, 47, 1005-1011. [CrossRef]

13. Li, G.; Yu, H.; Xu, L.; Ma, Q.; Chen, C.; Hao, Q.; Qian, Y. General synthesis of carbon nanocages and their adsorption of toxic compounds from cigarette smoke. Nanoscale 2011, 3, 3251-3257. [CrossRef]

14. Garlotta, D. A literature review of poly(lactic acid). J. Polym. Environ. 2001, 9, 63-84. [CrossRef]

15. Bao-shan, Y.; Tao, W.; Hao, W.; Jianbo, Z.; Geng, L.; Han, Z.; Jiao, X. Study on the influence of physical index of modified PLA filter rod on cigarette smoke index. In Proceedings of the 2020 3rd International Conference on Electron Device and Mechanical Engineering (ICEDME), Suzhou, China, 1-3 May 2020; pp. 494-496.

16. Ke, W.; Miao, M.; Liu, B.; Wu, Q.; Liu, T. Structural characteristics and properties of polylactic acid (PLA) and cellulose triacetate (CTA) fibers for heat-not-burn (HNB) cigarettes. IOP Conf. Ser. Earth Environ. Sci. 2021, 719, 042044. [CrossRef]

17. Tao, W.; Bao-shan, Y.; Hao, W.; Han, Z.; Jiao, X.; Jianbo, Z.; Geng, L. Safety Evaluation of Polylactic Aid Cgarette. In Proceedings of the 2020 3rd International Conference on Electron Device and Mechanical Engineering (ICEDME), Suzhou, China, 1-3 May 2020; pp. 222-224.

18. Zhang, M.; Li, X.H.; Gong, Y.D.; Zhao, N.M.; Zhang, X.F. Properties and biocompatibility of chitosan films modified by blending with PEG. Biomaterials 2002, 23, 2641-2648. [CrossRef]

19. Sundararajan, S.; Samui, A.B.; Kulkarni, P.S. Shape-stabilized poly(ethylene glycol) (PEG)-cellulose acetate blend preparation with superior PEG loading via microwave-assisted blending. Sol. Energy 2017, 144, 32-39. [CrossRef]

20. Şentürk, S.B.; Kahraman, D.; Alkan, C.; Gökçe, İ. Biodegradable PEG/cellulose, PEG/agarose and PEG/chitosan blends as shape stabilized phase change materials for latent heat energy storage. Carbohyd. Polym. 2011, 84, 141-144. [CrossRef]

21. Gök, Ö.; Alkan, C.; Konuklu, Y. Developing a poly(ethylene glycol)/cellulose phase change reactive composite for cooling application. Sol. Energy Mater. Sol. Cell. 2019, 191, 345-349. [CrossRef]

22. Peponi, L.; Sessini, V.; Arrieta, M.P.; Navarro-Baena, I.; Sonseca, A.; Dominici, F.; Gimenez, E.; Torre, L.; Tercjak, A.; López, D.; et al. Thermally activated shape memory effect on biodegradable nanocomposites based on PLA/PCL blend reinforced with hydroxyapatite. Polym. Degrad. Stab. 2018, 151, 36-51. [CrossRef]

23. Costa, L.M.M.; Mattoso, L.H.C.; Ferreira, M. Electrospinning of PCL/natural rubber blends. J. Mater. Sci. 2013, 48, 8501-8508. [CrossRef]

24. Liang, J.; Zhao, H.; Yue, L.; Fan, G.; Li, T.; Lu, S.; Chen, G.; Gao, S.; Asiri, A.M.; Sun, X. Recent advances in electrospun nanofibers for supercapacitors. J. Mater. Chem. A 2020, 8, 16747-16789. [CrossRef]

25. Parbey, J.; Xu, M.; Lei, J.; Espinoza-Andaluz, M.; Li, T.S.; Andersson, M. Electrospun fabrication of nanofibers as high-performance cathodes of solid oxide fuel cells. Ceram. Int. 2020, 46, 6969-6972. [CrossRef]

26. Bhardwaj, N.; Kundu, S.C. Electrospinning: A fascinating fiber fabrication technique. Biotechnol. Adv. 2010, $28,325-347$. [CrossRef] [PubMed]

27. Subbiah, T.; Bhat, G.S.; Tock, R.W.; Parameswaran, S.; Ramkumar, S.S. Electrospinning of nanofibers. J. Appl. Polym. Sci. 2005, 96, 557-569. [CrossRef]

28. Bognitzki, M.; Czado, W.; Frese, T.; Schaper, A.; Hellwig, M.; Steinhart, M.; Greiner, A.; Wendorff, J.H. Nanostructured fibers via electrospinning. Adv. Mater. 2001, 13, 70-72. [CrossRef]

29. Myndrul, V.; Vysloužilová, L.; Klápšt'ová, A.; Coy, E.; Jancelewicz, M.; Iatsunskyi, I. Formation and photoluminescence properties of $\mathrm{ZnO}$ nanoparticles on electrospun nanofibers produced by atomic layer deposition. Coatings 2020, 10, 1199. [CrossRef]

30. Ji, S.M.; Tiwari, A.P.; Kim, H.Y. Graphene oxide coated zinc oxide core-shell nanofibers for enhanced photocatalytic performance and durability. Coatings 2020, 10, 1183. [CrossRef]

31. Barhoum, A.; Pal, K.; Rahier, H.; Uludag, H.; Kim, I.S.; Bechelany, M. Nanofibers as new-generation materials: From spinning and nano-spinning fabrication techniques to emerging applications. Appl. Mater. Today 2019, 17, 1-35. [CrossRef]

32. Xue, J.; Wu, T.; Dai, Y.; Xia, Y. Electrospinning and electrospun nanofibers: Methods, materials, and applications. Chem. Rev. 2019, 119, 5298-5415. [CrossRef]

33. Aruna, S.T.; Balaji, L.S.; Senthil Kumar, S.; Shri Prakash, B. Electrospinning in solid oxide fuel cells-A review. Renew. Sustain. Energy Rev. 2017, 67, 673-682. [CrossRef] 
34. Costa, L.M.M.; Bretas, R.E.S.; Gregorio, R., Jr. Effect of solution concentration on the electrospray/electrospinning transition and on the crystalline phase of PVDF. Mater. Sci. Appl. 2010, 1, 247-252. [CrossRef]

35. Bi, C.; Li, X.; Xin, Q.; Han, W.; Shi, C.; Guo, R.; Shi, W.; Qiao, R.; Wang, X.; Zhong, J. Effect of extraction methods on the preparation of electrospun/electrosprayed microstructures of tilapia skin collagen. J. Biosci. Bioeng. 2019, 128, 234-240. [CrossRef]

36. Haroosh, H.J.; Chaudhary, D.S.; Dong, Y. Electrospun PLA/PCL fibers with tubular nanoclay: Morphological and structural analysis. J. Appl. Polym. Sci. 2012, 124, 3930-3939. [CrossRef]

37. Casasola, R.; Thomas, N.L.; Trybala, A.; Georgiadou, S. Electrospun poly lactic acid (PLA) fibres: Effect of different solvent systems on fibre morphology and diameter. Polymer 2014, 55, 4728-4737. [CrossRef]

38. Altinisik, A.; Yurdakoc, K. Chitosan/poly(vinyl alcohol) hydrogels for amoxicillin release. Polym. Bull. 2014, 71, 759-774. [CrossRef]

39. Wang, Q.; Liu, P.; Liu, P.; Gong, T.; Li, S.; Duan, Y.; Zhang, Z. Preparation, blood coagulation and cell compatibility evaluation of chitosan-graft-polylactide copolymers. Biomed. Mater. 2014, 9, 015007. [CrossRef] [PubMed]

40. Henderson, M.A. The interaction of water with solid surfaces: Fundamental aspects revisited. Surf. Sci. Rep. 2002, 46, 1-308. [CrossRef] 